Original Article

\title{
ANALYSIS OF MOLECULAR DOCKING EFFICIENCY OF CLEISTANTHIN-A, AS AN ALTERNATIVE FOR NICOTINE ADDICTION
}

 HOPPER $^{4}$}

1Department of Biotechnology, Sathyabama Instittue of Science and Technology, Chennai, India, ${ }^{2}$ Department of Biotechnology, Guru Nanak College, Velacherry, Chennai, India, ${ }^{3}$ Department of Biotechnology, Hindustan College of Arts and Science, Chennai, India, ${ }^{4}$ Department of Bioinformatics, School of Bioengineering, Faculty of Engineering and Technology, SRM Institute of Science and Technology, Kattankulathur, Chennai, India Email: a.amalraaj@gmail.com

Received: 05 Jan 2018 Revised and Accepted: 08 Mar 2018

\section{Abstract}

Objective: The present research was aimed to understand the molecular docking efficiency of a plant-derived compound cleistanthin-A and a common ingredient in tobacco consumption nicotine with nicotinic acetylcholine receptor (nAChR).

Methods: The 3-D structure of nAChR was retrieved from the protein data bank (ID 5AFH). Ligand was obtained from the PUBCHEM. The in silico protocol comprised of three steps: high-throughput virtual screening (HTVS), standard precision (SP) and extra precision (XP). The screened molecules were ranked accordingly using glide score. Schrödinger tool was used to perform the docking analysis.

Results: The binding efficiency of the nicotine and cleistanthin-A was found to be docked at the cys-cys loop of the receptor. Based upon the glide score and glide energy it can be reported that, nicotine binding can be inhibited by the binding of cleistanthin-A to the nAChR.

Conclusion: The docking efficiency of cleistanthin-A was good compared to nicotine towards nAChR. Hence, cleistanthin-A was derived as a better choice as an alternative for nicotine in smoke therapy.

Keywords: Nicotine, Cleistanthin-A, Schrödinger tool, Molecular docking, nAChR

(c) 2018 The Authors. Published by Innovare Academic Sciences Pvt Ltd. This is an open access article under the CC BY license (http://creativecommons.org/licenses/by/4.0/] DOI: http://dx.doi.org/10.22159/ijpps.2018v10i4.24637

\section{INTRODUCTION}

India is extremely famous for its mega biodiversity resources [1]. Medical uses of various herbal formulations were highlighted in the Ayurvedic literature sidhasarasamhitawritten during the $8^{\text {th }}$ century [2]. The economic importance of Indian plant species are increasing globally because of the medicinal properties of their active chemical constituents [3]. All parts of the plant like leaves, roots, stem, flowers, seeds and fruits were used in active drug formulations [4]. Hence, most of our researchers were focused on plants and plantderived constituents to address various kinds of medical issues.

The habit of cigarette smoking is very fatal throughout the world. In spite of so many anti-smoking therapies available, the smoking habit still continues among all the groups of people. Nicotine triggers dopamine secretion in the brain and thus the habit continues and smoking becomes a chronic disorder. Because of routine smoking nicotine enters into the human body and causes deleterious effects such as lung cancer and opportunistic disorders like tuberculosis. If an alternative molecule is discovered, this can reverse or block the effect of nicotine [5]. The unique binding orientation of two different molecules with each other can be detected using molecular docking analysis [6].

Nicotine (fig. 1) binds to the same neuroreceptor to which acetylcholine binds. There are five domains namely $\alpha 1-10, \beta 1-4, \gamma, \delta$, $\varepsilon$ selected from a group of seventeen homologous polypeptide sequences which forms the transmembrane part of the receptor [7]. There are four transmembrane segments and external $\mathrm{N}$-terminal forms the cys-cys loop on each of the receptors and have a molecular weight of $290 \mathrm{kDa}[8,9]$. The function of nAChR is hampered when nicotine binds to it.

The ligand binding domain is $20 \mathrm{~A}^{\circ}$ long and $40 \mathrm{~A}^{\circ}$ in diameter, which spreads from membrane surface on the opposite side of the pore. The intracellular domain has a narrow lateral opening for the ions [10].

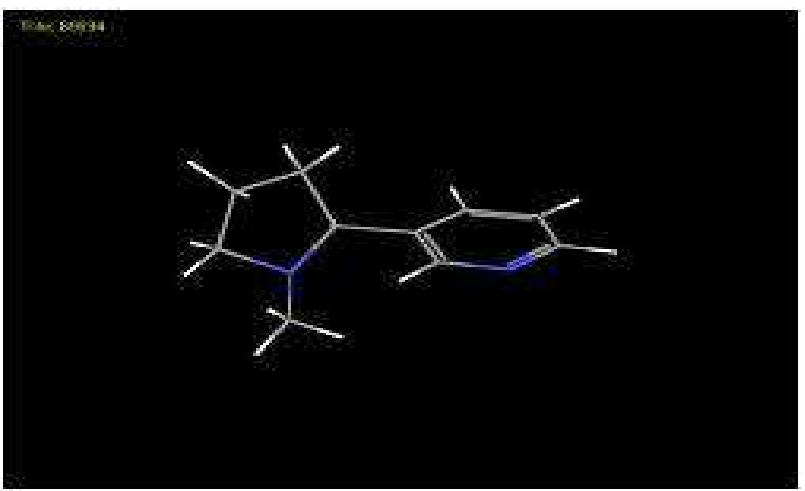

Fig. 1: Structure of nicotine

Cleistanthin-A (fig. 2) is the active constituent of the poisonous plant, Cleistanthus collinus (Roxb.) Benth. ex Hook. f. Cleistanthin-A compound was first isolated and named as cleistanthin [11]. Another related compound was later identified from the same plant species. Hence, cleistanthin was renamed as cleistanthin-A, lately identified compound was named as cleistanthin-B [12]. CleistanthinA, though belongs to the poisonous plant, the recent publications reported many of its therapeutic properties. The anti-hypersensitive effect and diuretic effect are few examples of this category $[13,14]$. The anticancer potentials of cleistanthin-A were also reported by 
many researchers [15-17]. The present study was aimed to analyze the docking properties of cleistanthin-A against nAChR.



Fig. 2: Structure of cleistanthin-A

\section{MATERIALS AND METHODS}

\section{Receptor}

The 3-D structure of nAChR (fig. 3) with $2.4 \mathrm{~A}^{\circ}$ resolution was retrieved from the protein data bank (ID $5 \mathrm{AFH}$ ).

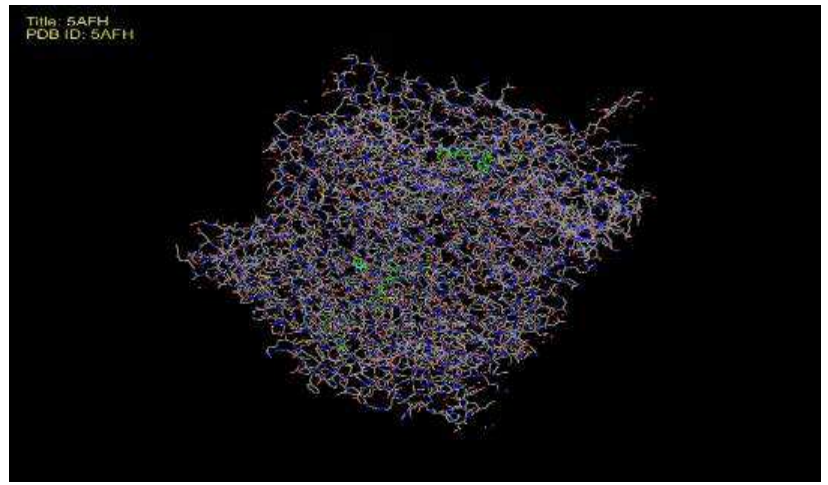

Fig. 3: Structure of nAChR

\section{Ligand preparation}

Ligand for the present study was obtained from the PUBCHEM. The compound's structural coordinates were retrieved in the mol format. Structural coordinates were converted from 2-D to 3-D formats and were energetically minimized using the optimized potentials for liquid simulations (OPLS) force field. The chiral centre of the ligand was used to retain the original state and this also helps in the prevention of stereoisomer generation.

\section{Structure-based virtual screening}

Virtual screening is one of the potential screening methodologies used to identify the possibilities of the ligand-receptor binding efficiency. The in silico protocol comprised of three steps: HTVS, SP and XP. The screened molecules were ranked accordingly by using glide scores [18].

\section{Glide docking}

For ligand docking, the glide version 6.1 protocol was used in the present study. The active site of the prepared protein was defined using default parameters of receptor-grid generation present in the glide module. Once the receptor grid was generated, the ligands were docked using the XP docking protocol [19]. The receptorligand complex interaction scores, i.e., glide scores, were calculated based on the following equation:

Glide score $=0.065 \times v d W+0.130 \times$ Coul + Lipo + Hbond + Metal + BuryP + RotB+Site where $v d W$ signifies van der Waals energy, Coul represents Coulomb energy, Lipo denotes lipophilic term derived from hydrophobic grid potential, Hbond means hydrogen-bonding term, Metal means metal-binding term, BuryP implies penalty for buried polar groups, RotB infers penalty for freezing rotatable bonds, and Site means polar interactions in the active site.

\section{RESULTS}

The molecular docking for nicotine and cleistanthin-A on nAChR was performed using the Schrödinger tool (fig. 4 and 5).

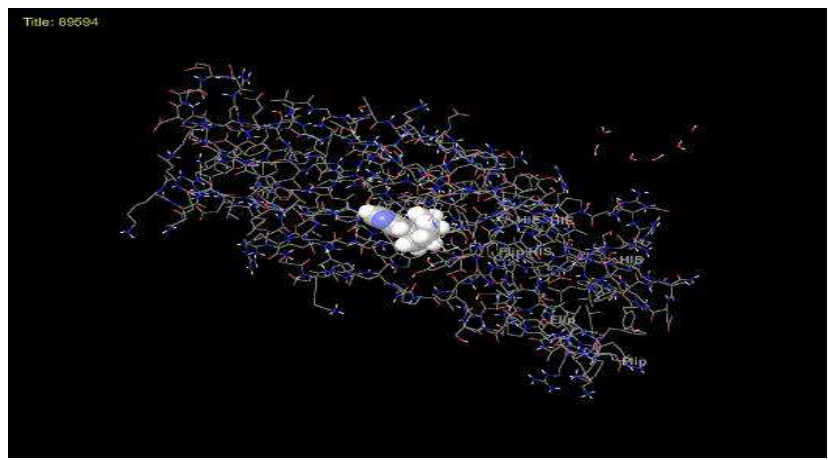

Fig. 4: Docking interaction of nicotine with nAChR

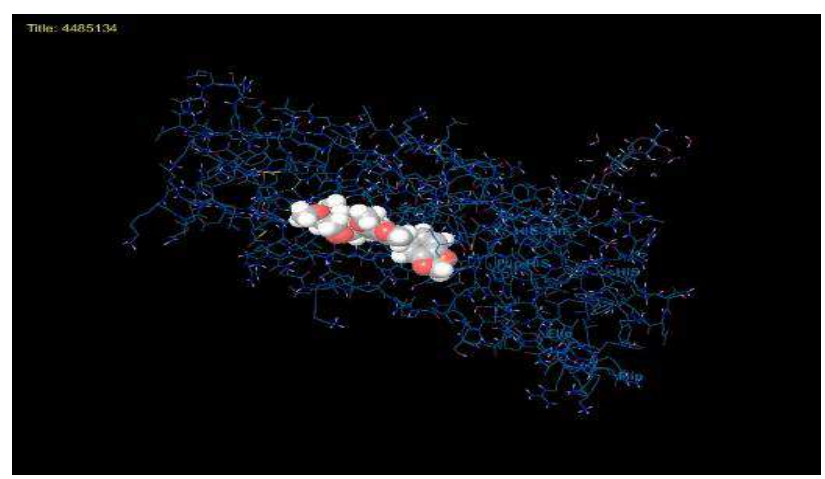

Fig. 5: Docking interaction of cleistanthin-A with nAChR

The in silico screening of the ligand and the receptor was proved useful in drug discovery. This tool gives a higher resolution of the target receptors and the docking molecules. The induced fit docking predicts the molecule, docking with its receptor. Hence, in this present investigation, through schrödinger tool, the binding efficiency of the nicotine and cleistanthin-A was found to be docked at the cys-cys loop of the receptor. The glide score and the glide score energy values were calculated and tabulated (tables 1 and 2).

Table 1: Docking value of nicotine

\begin{tabular}{lllllllll}
\hline Title & EntryID & Entry name & PDB title & $\begin{array}{l}\text { PDB } \\
\text { ID }\end{array}$ & PDB classification & $\begin{array}{l}\text { Docking } \\
\text { score }\end{array}$ & $\begin{array}{l}\text { XPGscore } \\
\text { Glide } \\
\text { score }\end{array}$ & $\begin{array}{l}\text { Glide } \\
\text { energy }\end{array}$ \\
\hline 5AFH & 1 & 5AFH-RECEPTOR.1 & ALPHA 7-A & 5AFH & Transport Protein & -6.095 & -6.146 & - \\
Nicotine & 2 & $\begin{array}{l}\text { STRUCTURE } \\
\text { 39594 }\end{array}$ & & & & & -20.076 & \\
\hline
\end{tabular}


Table 2: Docking value of cleistanthin-A

\begin{tabular}{|c|c|c|c|c|c|c|c|c|c|}
\hline Title & $\begin{array}{l}\text { Entry } \\
\text { ID }\end{array}$ & Entry name & PDB title & $\begin{array}{l}\text { PDB } \\
\text { ID } \\
\end{array}$ & $\begin{array}{l}\text { PDB } \\
\text { classification }\end{array}$ & $\begin{array}{l}\text { Docking } \\
\text { score }\end{array}$ & $\begin{array}{l}\text { XPG } \\
\text { score }\end{array}$ & $\begin{array}{l}\text { Glide } \\
\text { score }\end{array}$ & $\begin{array}{l}\text { Glide } \\
\text { energy }\end{array}$ \\
\hline $5 \mathrm{AFH}$ & 1 & 5AFH-RECEPTOR.1 & $\begin{array}{l}\text { ALPHA7- } \\
\text { A }\end{array}$ & $5 \mathrm{AFH}$ & $\begin{array}{l}\text { Transport } \\
\text { Protein }\end{array}$ & -4.309 & -4.309 & - & -30.899 \\
\hline $\begin{array}{l}\text { Cleistanthin-A. } \\
1\end{array}$ & 2 & STRUCTURE3D_CID_89594.1 & & & & & & & \\
\hline
\end{tabular}

\section{DISCUSSION}

As the entire bioinformatics was based upon the prediction, there was always thirst for tools with high precision. Many tools were quite frequently used in the field of biotechnology and pharmaceutical industries [20]. The Schrödinger tool was a suitable pharmacophore modelling software which helped the researchers to create 3-D structure-activity relationships between the receptor and ligand structure. It was also a versatile tool for the researcher to create and save multi-conformer database for later screening, database set-up and multi-pharmacophore screening (info@ Schrödinger. com).

Grid-based ligand docking with energetic commonly called as glide [21]. Glide was designed to perform positional, orientation and conformational positioning. This also enabled the ligand-receptor to be screened through large computational libraries with high speed. The calculation of glide score was based upon chem score [22]. Glide, placed the ligand at the centre site point of the receptor, if the match was accurate otherwise skipped over the point if there was no match. Glide energy was modified by van der Waals interaction. The minimum energy docked complex was found in the majority of similar docking conformations. Finally, the lowest-energy docked complex was selected for further study.

\section{CONCLUSION}

India is the third largest country in tobacco production, and Indians are the second largest consumers of tobacco, according to Global Adult Tobacco Survey (GATS 2017). It is a herculian task for our government to create awareness and control the adverse effects of tobacco that includes cancer and tuberculosis. Based upon the present study, the binding efficiency of the cleistanthin-A was good compared to the binding efficiency of nicotine with nAChR. Hence, the phytoconstituent cleistanthin-A could be a considered better choice for the pharmaceutical industries to generate an alternative for nicotine in smoke therapy. The formulations of cleistanthin-A as a drug can largely help in the reduction of the withrawal symptoms due to the prolonged addiction of nicotine.

\section{AUTHORS CONTRIBUTIONS}

All the authors contributed equally

\section{CONFLICT OF INTERESTS}

All authors of this publication declare that there are no conflicts of interest in publishing this research article.

\section{REFERENCES}

1. Adikari PR, Paul SB. Medicinally important plant Cleome gynandra: a phytochemical and pharmacological explanation. Asian J Pharm Clin Res 2018;11:21-9.

2. Nishteswar K, Unnikrishnan V. Herbal monotherapy of sidhasarasamhita. J Crit Rev 2016;4:12-6.

3. Ravindran AE, Thoppil JE. Phytochemical profiling and antibacterial efficacy screening of Aglaia malabarica sasidh. Int J Curr Pharm Res 2017;10:20-2.

4. Venkatachalam CD, Sengottian M, Sengodan T. Formulation and evaluation of polyherbal floating effervescence tablet containing Pedalium murex and Tribulus terrestris fruit extracts. Int J Appl Pharm 2017;9:10-5.
5. PA Crooks, MT Bardo, LP Dwoskin. Nicotinic receptor antagonists as treatments for nicotine abuse. Adv Pharmacol 2014;69:513-51.

6. Merugu R, Singh KV. Molecular docking of amitriptyline to ceruloplasmin, retinol-binding protein and serum albumin. Asian J Pharm Clin Res 2018;11:169-75.

7. Kalamida D, Poulas K, Avramopoulou V, Fostieri E, Lagoumintzis G, Lazaridis $\mathrm{K}$, et al. Muscle and neuronal nicotinic acetylcholine receptors structure, function and pathogenicity. FEBS J 2007;274:3799-845.

8. Sine SM, Engel AG. Recent advances in Cys-loop receptor structure and function. Nature 2006;440:448-55.

9. Grace B, David NL, Jerome H, Roderic GE, Michael LK. Multiple binding sites for the general anesthetic isoflurane identified in the nicotinic acetylcholine receptor transmembrane domain. Proc Natl Acad Sci U S A 2010;107:14122-7.

10. Unwin N. Refined structure of the nicotinic acetylcholine receptor at $4 A^{\circ}$ resolution. J Mol Biol 2004;346:967-89.

11. Govindachari TR, Sathe S, Viswanathan N, Pai BR, Srinivasan M. Chemical constituents of Cleistanthus collinus (Roxb.). Tetrahedron 1969;25:2815-21.

12. Lakshmi TG, Srimannarayana G, Subbha Rav NV. A new glycoside from Cleistanthus collinus. Curr Sci 1970;39:395-6.

13. Priyadharsini RP, Parasuraman SR, Raveendran R. Evaluation of the antihypertensive activity and alpha adrenergic receptor interaction of cleistanthins $A$ and B.J Basic Clin Pharm 2014;5:109-14.

14. Parasuraman S, Raveendran R. Diuretic effects of cleistanthin A and cleistanthin B from the leaves of Cleistanthus collinus in wistar rats. J Young Pharm 2012;4:73-7.

15. Pradeep Kumar CP, Shanmugam G. Anticancer potential of cleistanthin A isolated from the tropical plant Cleistanthus collinus. Oncol Res 1999;11:225-32.

16. Meenakshi J, Shanmugam G. Cleistanthin A, a diphyllin glycoside from Cleistanthus collinus, is cytotoxic to PHAstimulated (proliferating) human lymphocytes. Drug Dev Res 2000;51:187-90.

17. Sheng P, Hengji C, Lixiong G, Shaunglin C. Cleistanthin A inhibits the invasion and metastasis of human melanoma cells by inhibiting the expression of matrix metallopeptidase- 2 and -9. Oncol Lett 2017;14:6217-23.

18. Ganesh K, Veeramachaneni K, Kranthi R, Leela MC, Jayakumar SB, Venkateswara BT. High-throughput virtual screening with e-pharmacophore and molecular simulations study in the designing of pancreatic lipase inhibitors. Drug Des Dev Ther 2015;9:4397-412.

19. Aggeliki P, Serdar D, Panagiota $M$, George $K$, Thomas $M$. Development of accurate binding affinity predictions of novel renin inhibitors through molecular docking studies. J Mol Graph Model 2019;29:425-35.

20. Venkatachalam CM, Jiang X, Oldfield T, Waldman MJ. Ligand fit: a novel method for the shape-directed rapid docking of ligands to protein active sites. J Mol Graphics Model 2003;21:289-307.

21. Schr Odinger LLC. New York. The Glide 2.5 calculations used First Discovery, version 2.5021; 2003.

22. Eldridge MD, Murray CW, Auton TR, Paolini GV, Mee RP. Empirical scoring functions: The development of a fast empirical scoring function to estimate the binding affinity of ligands in receptor complexes. J Comput Aided Mol Des 1997; 11:425-45. 